\title{
Mapping of Wild Olive Trees: the Range, Distribution and Basic Attributes of Wild Olive Trees in AI Baha, Saudi Arabia, Using Remote Sensing Technology
}

\author{
III. Distribution and mapping of wild olive tree according to neighbouring tree species
}

\author{
Abdullah Saleh Al-Ghamdi \\ Department of Biology, College of Sciences, Al-Baha University, P.O. Box 400, Al-Baha 31982, Kingdom of Saudi Arabia \\ abdullah.saleh.alghamdi@gmail.com
}

\begin{abstract}
This study provides a detailed overview of the extent and distribution of wild olive trees in Al-Baha region according to neighbouring tree species. The study area was concentrated along the Sarah mountainat Al-Baha region, encompassing the districts Al-Qura, Al-Mandaq, Al-Baha, the southern part of Baljurashi, and a small portion of Qelwa, Mekhwa, and Al-Aqiq districts. This indicates that the wild olive prefers to grow in high foggy mountain conditions, which a previous study determined as a medium-high vegetation density zone. The information extracted from the high-resolution PLEIADES satellite image reveals that the districts of AlMandaq and Al-Baha have a higher density of wild olives with more juniper neighbouring. On the other hand, the districts of Al-Qura and Al-Baljurashi have a lower density of wild olives but more acacia neighbouring. Meanwhile, the districts of Al-Aqiq, Qelwa, and Mekhwa have the least density of wild olives with more juniper neighbouring; however, Qelwa has more 'other' species neighbouring. Further analysis of the imagery by automatic measurement of olive trees found that the wild olive tree associates its occurrence with certain species. The neighbouring species was identified within a five-meter radial distance from wild olives. The result indicates that juniper (40.2\%) and acacia (36.0\%) are the two main species that neighbour wild olives, with acacia found more dominantly in both the districts of Al-Qura and Baljurashi. Distinctly, Qelwa was found to have many other as neighbouring species (42.3\%). The overall accuracy of the interpretation of species was $89.2 \%$, with the producer and user accuracy for wild olive interpretation being $93.7 \%$ and $88.3 \%$, respectively. This information will be essential to identifying the landscape preference of wild olives in the Al-Baha region.
\end{abstract}

Keywords: Wild olive tree, mapping, extent, distribution, Al-Baha region, Remote sensing, neighbouring tree species, acacia, juniper

\section{Introduction}

\section{Wild Olive Tree}

Olea oleaster, or the wild-olive, has been considered by various botanists as a valid species and a subspecies of the cultivated olive tree, Olea europea, which is a tree of multiple origins (Besnard and Berville, 2000) that was domesticated, as it seems now, in various places during the fourth and third millennia BCE, in selections drawn from varying local populations (Besnard and Baradat, 2001).

Today, as a result of natural hybridisation and the very ancient domestication and extensive cultivation of olive trees throughout the Mediterranean Basin, wild-looking feral forms of olive, called 'oleasters', constitute a complex of populations potentially ranging from feral forms to the wild-olive (Lumaret, Ouazzani, Michaud, and Vivie, 2004).

The wild olive is a tree of the maquis shrubland, itself in part the result of the long presence of mankind. The droughttolerant sclerophyllous wild olive tree is believed to have originated in the Mediterranean Basin. It still provides the hardy and disease-resistant rootstock on which cultivated olive varieties are grafted (Breton et al., 2006).

Meanwhile, the wild olive is also reportedly native to a North American evergreen tree that reaches a height of 20 feet with a10-15 feet crown spread. This small tree is very rarely found and is even reportedly close to extinction. The olivelike white fruits that are produced have a sweet flesh that is relished by birds and other wild life and, although edible to man, should not be eaten in large quantities. In the United
States of America, another olive tree species known as the Russian olive (Elaeagnus angustifolia L.) was considered as an exotic invasive weed. This thorny shrub or tree originated from South-eastern Europe and Western Asia, and Katzand Shafroth (2003) reported that it was intentionally introduced and planted in the United States for windbreaks, erosion control, wildlife habitat, and other horticultural purposes. This tree was then observed to be very well adapted to semi arid and saline environments. Early in the $20^{\text {th }}$ century, the Russian olives caped cultivation and spread, particularly into the large moist riparian environments in arid or semiarid regions of the western United States (Stannard et al., 2002).

\section{Mapping Wild Olive Trees Using Remote Sensing}

Classifying and mapping vegetation is an important technical task for managing natural resources because vegetation provides a base for all living beings and plays an essential role in affecting global climate change, such as influencing terrestrial $\mathrm{CO}_{2}$ (Xiao et al., 2004).Vegetation mapping further presents valuable information for understanding natural and man-made environments through quantifying vegetation cover from local to global scales at a given time point or over a continuous period. Obtaining the current states of vegetation cover is critical to initiating vegetation protection and restoration programs (Egbert et al., 2002).

Traditional methods (e.g. field surveys, literature reviews, map interpretation, and collateral and ancillary data analysis) have been not effective in acquiring mass vegetation covers because they are time consuming, data lagged, and often too expensive. Meanwhile, remote sensing offers a practical and economical means to study vegetation cover changes, 
especially over large areas (Langley et al., 2001; Nordberg and Evertson, 2003).

Because of the potential capacity for systematic observations at various scales, remote sensing technology extends possible data archives from the present time to over several decades prior. Considering this advantage, researchers and application specialists have made significant efforts to delineate vegetation covers from local to global scales by applying remote sensingimagery. Since then, numerous efforts have been taken at regional or national levels to map wild olive trees using remote sensing. An example is a pilot project initiated to develop a cost-effective method for mapping the Russian olive (Elaeagnus angustifolia L.), an invasive tree species, from scanned large-scale aerial photographs. A study area was established along a riparian zone within a semiarid region of the Fishlake National Forest, located in central Utah.Two scales of natural colour aerial photographs $(1: 4,000$ and 1:12,000) were evaluated. Feature Analyst, an extension of ArcGIS and several image processing software packages, was used to map the invasive tree. Overall, Feature Analyst located Russian olive (RO) throughout the imagery with a relatively high degree of accuracy. For the map derived from 1:4,000-scale photographs, the software correctly located the tree in $85 \%$ of all four-by-four meter transect cells where the Russian olive was actually present. However, smaller trees were sometimes missed, and the size of trees and groups of trees were frequently underestimated. The map derived from 1:4,000-scale photographs was only slightly more accurate than the map derived from the 1:12,000-scale photographs, suggesting that small-scale photography may be adequate to map the RO(Hamilton etal., 2006).

Another attempt to test the ability of remote sensing imagery to mapolive groves and their attributes was conducted in Australia. Specifically, this attempt aimed to discriminate olive cultivars and detect and interpret their within-field spatial variability. Using high spatial resolution $(2.8 \mathrm{~m})$ QuickBird multispectral imagery acquired over Yallamundi (southeast Queensland) on December 24, 2003, both visual interpretation and statistical (divergence) measures were employed to discriminate olive cultivars. Similarly, the detection and interpretation of within-field spatial variability was conducted on enhanced false-color composite imagery and confirmed by using statistical methods. Results showed that the two olive varieties (i.e. Kalamata and Frantoio) can be visually differentiated and mapped on the enhanced image based on texture. The spectral signature plots showed little difference in the mean spectral reflectance values, indicating that the two varieties have a very low spectral separability (Apan, 2004).

In relation to olives, a study that used conventional-colour and colour-infrared aerial photographs and vegetation indices was conducted in Spain to determine variations in the cover crop, bare soil, and tree areas in olive groves as affected by the season. The study found that early summer was the most suitable time to distinguish between cover crops and olive trees. Additionally, the study found that indices based on blue and red band reflectance values were suitable for the same process. (Peña-Barragán et al., 2004).
A recent study was conducted to enumerate the wild olive trees in the Al-Baha region and mapthe extent, distribution, and basic attributes such as the crown size of the tree usingremotesensing technology (AlGhamdi, $2020 \mathrm{a}, \mathrm{b}$ ).

\section{Study Area}

The most effective way to map the range of a plantspecies in an area is by demarcating a general bioclimatic envelope within biogeographic regions in which a species is known to have been found. This study required building a database of species that includes data on the distribution of species by geographic region, major habitat type, and elevation range (Price, 2004).

Similarly, in this study, due to the large area as well as to save time, cost, and energy, the initially selected study areas wereonly those with a high probability of wild olive tree presence indicated by high $\left(62 \mathrm{~km}^{2}\right)$ and medium $\left(766 \mathrm{~km}^{2}\right)$ density vegetation. However, since there was also a possibility of wild olive trees being found in a nearby area with lower vegetation density, the study area was expanded to the northern part with low vegetation canopy density but not to the southern part because this part of Al-Mekhwah and Qelwa has a steep slope towards Tehama. This totalled the overall study area $1,991 \mathrm{~km}^{2}$ (Figure.1,and Table 1), which is just $18 \%$ of the whole Al-Baha region. The study area covers almost all areas in Al-Mandaq and Al-Baha districts, and $58.5 \%$ of the study area has low vegetation crown density (Al-Ghamdi, 2020 a).

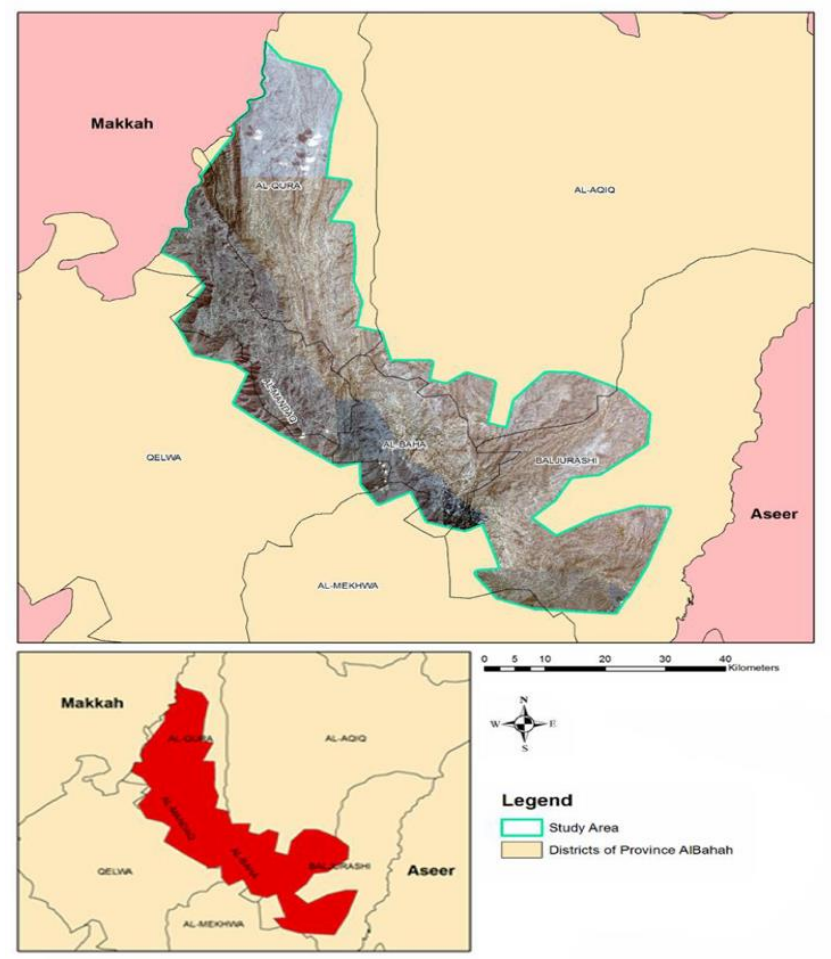

Figure 1: PLEIADES satellite image of study area (in red). 
Table 1: Study area extent according to districts

\begin{tabular}{|c|c|c|c|c|c|c|c|c|c|}
\hline \multicolumn{2}{|c|}{ District } & \multicolumn{7}{|c|}{ Vegetation Canopy Density } & \multicolumn{2}{c|}{ Study Area } \\
\hline Name & $\mathrm{KM}^{2}$ & High & $(\%)$ & Med. & $(\%)$ & Low & $(\%)$ & $\mathrm{KM}^{2}$ & $(\%)$ \\
\hline Al-Qura & 1,049 & 9 & 1.5 & 128 & 21.8 & 449 & 76.6 & 586 & 55.9 \\
\hline Al-Aqiq & 3,667 & 0 & 0.0 & 21 & 12.7 & 144 & 87.3 & 165 & 4.5 \\
\hline Al-Mandaq & 361 & 23 & 6.8 & 247 & 72.9 & 69 & 20.4 & 339 & 94 \\
\hline Al-Mekhwa & 1,949 & 3 & 11.1 & 24 & 88.9 & 0 & 0.0 & 27 & 1.4 \\
\hline Al-Baha & 298 & 17 & 5.9 & 106 & 36.9 & 164 & 57.1 & 287 & 96.4 \\
\hline Baljurashi & 1,505 & 7 & 1.4 & 162 & 32.0 & 337 & 66.6 & 506 & 33.6 \\
\hline Qelwa & 2,232 & 3 & 3.7 & 78 & 96.3 & 0 & 0.0 & 81 & 3.6 \\
\hline TOTAL & 11,060 & 62 & 3.1 & 766 & 38.5 & 1,163 & 58.4 & 1,991 & 18 \\
\hline
\end{tabular}

\section{Objectives}

The primary aim of this study is to produce high-quality, standardized maps to analyse the extent and distribution of wild olive trees according to neighbouring tree species to support a wide variety of resource assessment, management, and conservation of wild olive trees. It can act as a guide for standard national olive trees cultivation according to neighbouring tree species that will facilitate effective resource management by ensuring compatibility and widespread use of the information at multiple geographic scales throughout the Al-Baha federal and provincial agencies.

\section{Material and Method}

\section{Material and Data}

In this study, due to the mass area coverage and difficult terrain, satellite imagery was used as the mainsourcefor informationextraction.

The software used are as follows:

- ERDASImagine2014: Animageprocessingsoftware

- ArcGIS version 10.3: A GIS software to analyse the information extracted from satellite images

The data used in this study are as follows:

- PLEIADES satellite image dated May 15, 2016 (resolution $0.50 \mathrm{~m}$ x $0.5 \mathrm{~m}$ )

- Shuttle Radar Topography Mission (SRTM) (elevation data extraction)

- Digital boundaries of the Al-Baha region and districts

\section{Method}

The three main activities involved in this study were data collection involving satellite data procurement, data analysis, and field work. The satellite image LANDSAT- 8 dated May 15,2016 was used as the primary source for data extraction to identify the vegetated areas in the Al-Baha region. Upon downloading from the USGS website, Image LANDSAT-8 was processed for Normalized Differential Vegetation Indices (NDVI) to demarcate areas with vegetation or chlorophyll. Detailed activities of the workflow are shown in Figure 2.
Acquire satellite Pleaides image.

Resolution $0.5 \mathrm{~m} \times 0.5 \mathrm{~m}$

Pre- processing satellite Pleaides image.

Enhancement satellite Pleaides image.

Unsupervised Classification.

Extract tree areas.

Sample olive tree. Site collection.

Identify Spectral Signature of wild olive.

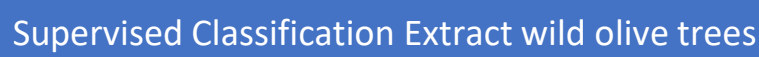

\section{Site Verification}

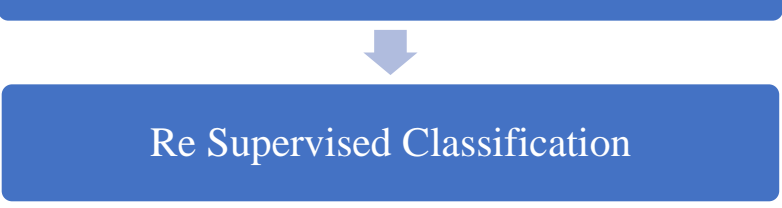

Identify and measure wild olive tree attribute (neighbouring tree species)

Generate wild olive tree distribution map according to (neighbouring tree species)

Figure 2: Work flowchart 


\section{Satellite Data Acquisition}

Remote sensing data acquired from PLEIADES satellite imagery (May 15, 2016) were purchased from Airbus Defence and Space through local agents. PLEIADES images provide high-resolution imagery, from 0.5 meters to 2.0 meters, of earth's land surface and polar regions. The PLEIADES swath covers $20 \mathrm{~km}$ at the nadir, and the satellites' high agility allows to acquire in the same pass a mosaic of images covering a larger area (up to $120 \mathrm{~km} \mathrm{x} 120$ $\mathrm{km}$ ), or stereoscopic images of $300 \mathrm{~km}$ length.

The PLEIADES bands are Panchromatic (450-830 nm), band 1 (blue, $430-550 \mathrm{~nm}$ ), band 2 (green, $500-620 \mathrm{~nm}$ ), band 3 (red, 590-710 nm), and band 4 (near infrared, 740$940 \mathrm{~nm})$.

\section{Satellite Image Pre-processing}

Image pre-processing is the process of making an image more interpretable for a particular application. It makes important features of raw, remotely sensed data more interpretable to the human eye. Image pre-processing includes data correction i.e. radiometric correction, geometric correction, and so on.

The remote sensing software ERDAS Imagine version 2014 was used to process the raw PLEIADES data including the radiometric correction, band combination, image enhancement, and other basic images processing system for data analyses. ERDAS Imagine is application with raster graphics editor abilities designed by ERDAS for geospatial applications. It is aimed mainly at geospatial raster data processing and allows users to prepare, display, and enhance digital images for mapping purposes in the geographic information system (GIS) software (Hexagonspatial, 2016).

\section{Image Enhancement and Filtering}

The selection of a suitable band combination is essential for PLEIADES to make enhanced images for visual interpretation. Removing blurring and noise, increasing the contrast, and revealing details are examples of enhancement operations (Rapp, 1996). There is no ideal or best type of image enhancement because the results are ultimately evaluated by humans, who subjectively judge whether a given image enhancement is useful (Jensen, 2005). In this study, the image was enhanced using Histogram Equalize to contrast the different land use.

\section{Spectral Signature}

The term spectral signature refers to the relationship between the wavelength (or frequency) of electromagnetic radiation (EMR) and the reflectance of the surface. The signature is affected by several factors including the material composition and structure. Some parts of the EMR spectrum, such as the microwave region, are more sensitive to surface structure than other regions. Spectral signature (or more often, sampled parts of it - such as bands of satellite imagery) infers details about the surface such as composition (e.g. vegetation, bare soil, etc.). Features are discriminable only if they have non-overlapping spectral signatures which can be normally viewed on the separability graph.

In this study, wild olive spectral signatures were extracted and compared from the image prior to the classification activity to ensure they were separable. The software specifically used was ENVI version 5.4, another remote sensing software that combinesadvanced spectral image processing and proven geospatial analysis technology with a modern, user-friendly interface specifically designed for more complicated images such as high-resolution images, hyperspectral images, SAR, and LIDAR.

\section{Ground SampleCollection}

A ground sample collection was required to acquire several locations of wild olive trees at various districts sites to act as the 'training samples' for supervised classification. These locations were marked as wild olivetree coordinates on the image and thespectral signature or digital number was recognized as a guide to search and demarcate othersimilar reflectance characteristics. In this project, about 30 points of wild olive trees were identified to run a supervised classification. These points are shown in Figure 3.

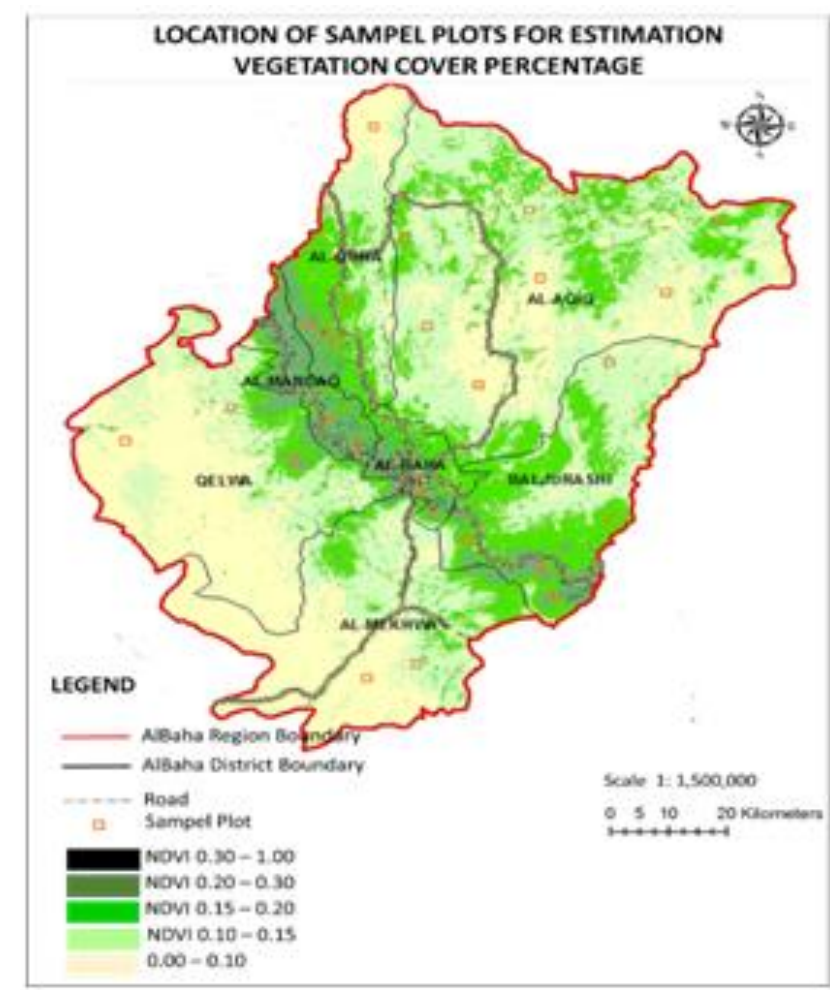

Figure 3: Location of plots for ground sample collection.

\section{Forest Inventory Design}

In this project, wild olive inventory was based on two major techniques:

- Aerial inventory: Using PLEIADES satellite images, measurements were taken of the whole study area. The area was divided to seven administrative districts: AlQura, Al-Aqiq, Al-Mandaq, Al-Baha, Baljurashi, Qehwa, and Al-Mekhwah. The attributes measured using aerial inventory were tree numbers and tree crown diameter.

- Ground inventory sampling plot: A certain number of plots statistically representing the whole area was randomly selected at site and the measurement was taken $100 \%$ within the plot. The inventory process comprised of designing the inventory, designing the forms of 
collecting the information, dividing the forest area into seven districts, describing the tree cover of each site, measuring all the trees crown diameter attribute within each sampling plot, and analysing the information obtained.

\section{Accuracy Assessment}

Accuracy assessment is the comparison of a classification with ground truth data to evaluate how well the classification represents the real world. Steps involved in accuracy assessment included determining number of samplings, determining the confidence building assessment, and sampling the design. In this project, the number of sampling followed the Krejcie and Morgan method, the assessment followed the producer/consumer accuracy, and the plots were selected based on random sampling technique.

\section{Determining the Number of Sampling}

For any research, the sample size of the study must be determined during the designing stage. However, before determining the sample size that needs to be drawn from the population, a few factors must be considered. According to Salant and Dillman (1994), the size of the sample is determined by four factors:

1) How much sampling error can be tolerated;

2) Population size;

3) How varied the population is with respect to the characteristics of interest; and

4) The smallest subgroup within the sample for which estimates are needed.

Using the above methods as a guideline, the following section used Krejcie and Morgan (1970) and the Cohen Statistical Power Analysis. Krejcie and Morgan is a commonly employed method for the estimation of sample size in research. Krejcie and Morgan (1970)used the following formula to determine sampling size:

$\mathrm{S}=\mathrm{X}^{2} \mathrm{NP}(1-\mathrm{P}) / \mathrm{d}^{2}(\mathrm{~N}-1)+\mathrm{X}^{2} \mathrm{P}(1-\mathrm{P})$

$\mathrm{S}=$ required sample size

$\mathrm{X}^{2}=$ the table value of chi-square for one degree of

freedom at the desired confidence level

$\mathrm{N}=$ the population size

$\mathrm{P}=$ the population proportion (assumed to be.50 since this would provide the maximum sample size)

$\mathrm{d}=$ the degree of accuracy expressed as a proportion (.05) In this study,

$\mathrm{S}=\mathrm{X}^{2} \mathrm{NP}(1-\mathrm{P}) / \mathrm{d}^{2}(\mathrm{~N}-1)+\mathrm{X}^{2} \mathrm{P}(1-\mathrm{P})$

$=3.841 * 236,250 * 0.95 *(1-0.95) / 0.05 * 0.05 *$

$(236,250-1)$

$=41,963 / 575.18$

$=73$

Therefore, 73 plots measuring $50 \mathrm{~m} \times 50 \mathrm{~m}$ were established in the study area.

\section{Determining the Sample Size}

When assessing the accuracy of remotely sensed data, each collected sample point is expensive; therefore, the sample size must be kept to a minimum. Yet, maintaining a large enough sample size is critical so that any analysis performed is statistically valid. Because of the large number of pixels in a remotely sensed image, traditional thinking about sampling does not often apply (Congalton, 1991). Hence, this study followed the most common plot size established for forest inventory of $50 \mathrm{~m}$ x $50 \mathrm{~m}$, which was similarly applied by El-Juhany and Aref (2012), for recent vegetation inventory at Al-Baha.

\section{Wild Olive Tree Neighbouring Species Attribute Measurement}

Measurement for attributes of the neighbouring species of wild olive trees for the whole study were done using both satellite PLEIADES imagery and direct measurement at the ground. Ground measurement was conducted during October 2016 with 73 plots measuring 50x 50m. Enumeration of neighbouring species was determined digitally using ArcGIS software based on the species identification on ERDAS software. In this project, neighbouring species were confined to those located within a five-meter radius from wild olive trees. Species were divided into three main categories: juniper, acacia, and others.

\section{Stratified Random Sampling}

From the vegetation map generated from the first phase study, the districts of Al-Baha were observed to have varying vegetation density considerably influenced by elevation. We may expect the measurement of wild olive trees to vary among the different districts. This has to be considered when we select a sample from the population so we obtain a sample representative of the population. This can be achieved by stratified sampling. A stratified sample is obtained by taking samples from each stratum or subgroup of a population. When we sample a population with several strata, we generally require that the proportion of each stratum in the sample should be the same as in the population.

Stratified sampling techniques are generally used when the population is heterogeneous, or dissimilar, where certain homogeneous, or similar, sub-populations can be isolated (strata). Simple random sampling is most appropriate when the entire population from which the sample is taken is homogeneous. Some reasons for using stratified sampling over simple random sampling are as follows:

a) The cost per observation in the survey may be reduced;

b) Estimates of the population parameters may be wanted for each sub-population; and

c) Increased accuracy at given cost.

As mentioned earlier, the stratification was based on district boundaries, and the number of plots are proportionate to district size. As the main portion of the study area was at a high elevation with a rugged terrain and was not easily accessible, the plots selected have to consider accessibility and road proximity. The trees located a bit further into the plot were remotely measured using laser range finder. In this project, verification was conducted on accuracy of the satellite image interpreted wild olive tree which was classified $100 \%$ throughout the whole study area. We used the same 73 inventory plots earlier established to reduce the time and energy.

\section{Results}

This study provided the extent and distribution of wild olive tree according to the neighbouring species and accuracy 
assessment results.

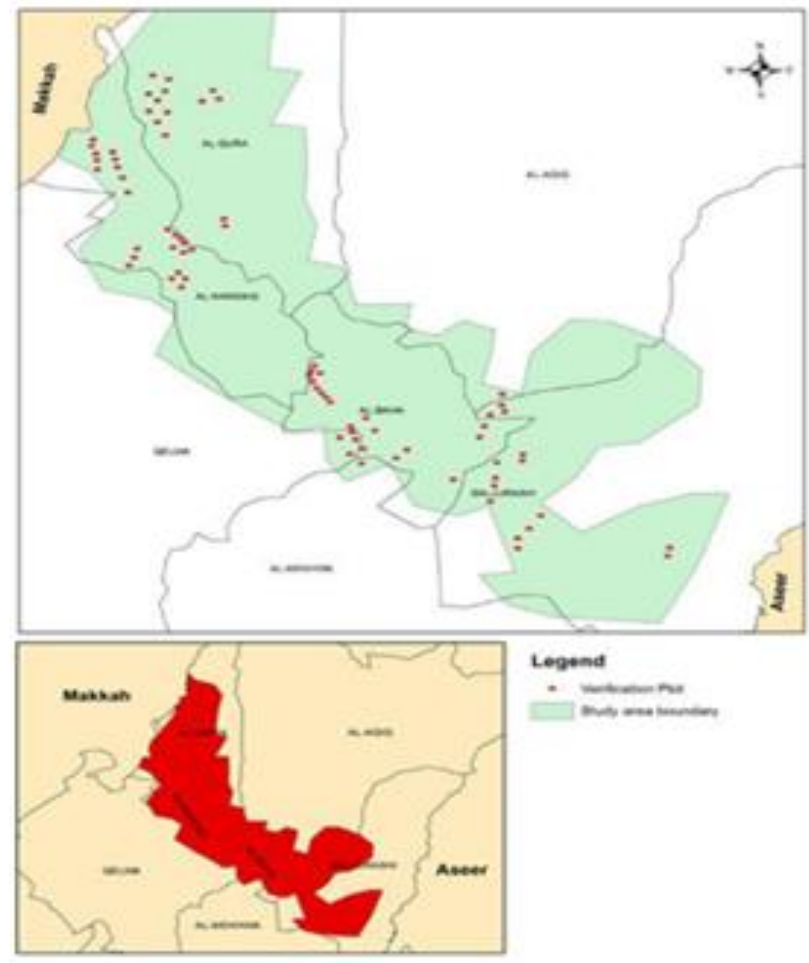

Figure 4: Location of plots for inventory and accuracy assessment

Extent of Wild Olive Tree According to Neighbouring Species
The results provided detailed information on the extent and distribution of wild olive trees according to neighbouring species surrounding them within a five-meter radius.It also provided standard high-quality maps of the extent and distribution of wild olive trees according to neighbouring tree species as well as the results of accuracy assessment.

Neighbouring species were automatically determined by enumerating within a five-meter radial buffer threshold from wild olive trees set by the software ArcGIS. Prior to that, PLEIADES satellite imagery was classified to determine wild olive trees, juniper, acacia, and other species using the software ERDAS.

Overall results show that the main species neighbouring wild olive trees is juniper (44.4\%), particularly in Al-Qura (78.3\%), Al-Mandaq (54.9\%), and Al-Mekhwa (48.5\%). Meanwhile, acacia was the more dominant neighbouring species in Bajurashi (43.8\%), followed by other species in Qelwa (42.3\%).Other species included Ochradenus baccauts, Dodonaea angustifolia, Terminalia brownii, Tamarix aphylla, and Ficus palmata, as shown in Table 2.

The abundance of juniper trees at Al-Mandaq, Al-Aqiq, and Al-Baha districts could possibly be attributed to its higher elevations and the rugged nature of its mountains (especially in the past before incision modern roads) that protect its forest from extensive exploitation because it not easily accessible. Meanwhile, the small size of the trees and irregular growth show that they were cut in the past. (Figures 3, 4, 5, 6, 7, 8, 9, 10).

Table 2: Extent of Wild Olive Tree with Neighbouring Species

\begin{tabular}{|c|c|c|c|c|c|c|c|c|c|}
\hline \multirow{3}{*}{ District } & \multirow{3}{*}{$\begin{array}{c}\text { Study } \\
\text { Area } \mathrm{Km}^{2}\end{array}$} & \multirow{3}{*}{$\begin{array}{c}\text { Total Number } \\
\text { of Wild Olive } \\
\text { Trees }\end{array}$} & \multirow{3}{*}{$\begin{array}{c}\text { Total Number of } \\
\text { Neighbouring } \\
\text { Trees* }\end{array}$} & \multicolumn{6}{|c|}{ Number of Neighbouring Trees } \\
\hline & & & & \multicolumn{2}{|c|}{ Juniper } & \multicolumn{2}{|c|}{ Acacia } & \multicolumn{2}{|c|}{ Others } \\
\hline & & & & number & $\%$ & number & $\%$ & number & $\%$ \\
\hline Al-Qura & 586 & 129,903 & 79,521 & 29,525 & 37.1 & 46,250 & 58.2 & 3746 & 4.7 \\
\hline Al-Aqiq & 165 & 3,433 & 2,296 & 1347 & 58.7 & 836 & 36.4 & 113 & 4.9 \\
\hline Al-Mandaq & 339 & 208,034 & 148,886 & 78,219 & 52.5 & 21,359 & 14.3 & 49,308 & 33.1 \\
\hline Al-Mekhwa & 27 & 11,851 & 41,875 & 20293 & 48.5 & 14592 & 34.8 & 6990 & 16.7 \\
\hline Al-Baha & 287 & 161,802 & 193,920 & 71,354 & 36.8 & 61,443 & 31.7 & \begin{tabular}{|l|}
61,123 \\
\end{tabular} & 31.5 \\
\hline Baljurashi & 506 & 178,801 & 102,297 & 30,522 & 29.8 & 64,271 & 62.8 & 7504 & 7.3 \\
\hline Qelwa & 81 & 24,070 & 35,493 & 11743 & 33.1 & 8742 & 24.6 & 15008 & 42.3 \\
\hline TOTAL & 1,991 & 717,894 & 604,288 & 243,003 & 40.2 & 217,493 & 36.0 & 143,792 & 23.8 \\
\hline
\end{tabular}

*neighbouring trees are those surrounding wild olive trees within a 5-meter radius 


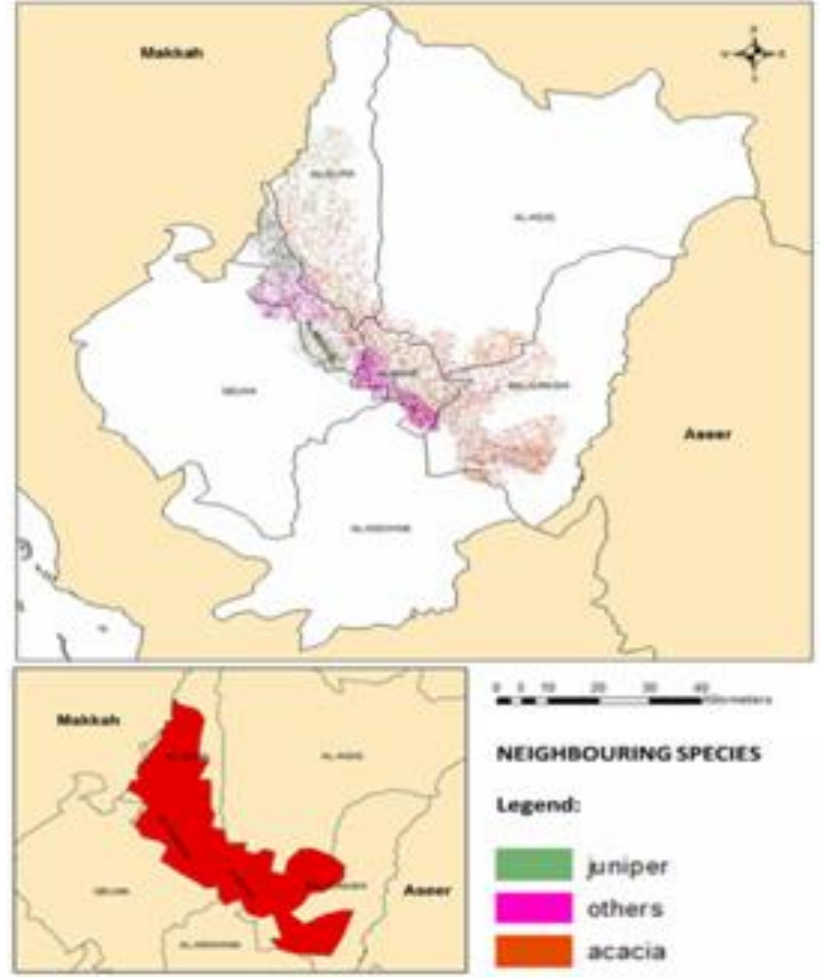

Figure 5: Distribution of neighbouring species in the AlBaha region.

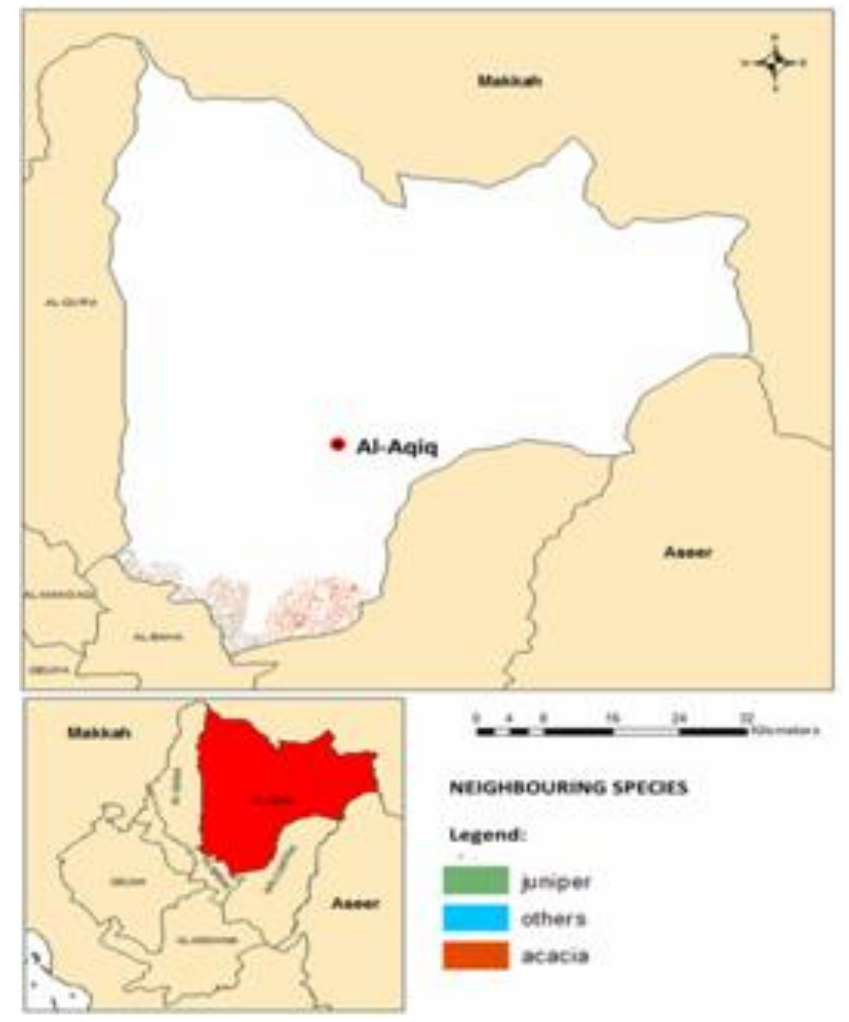

Figure 6: Distribution of neighbouring species in the AlAqiq district

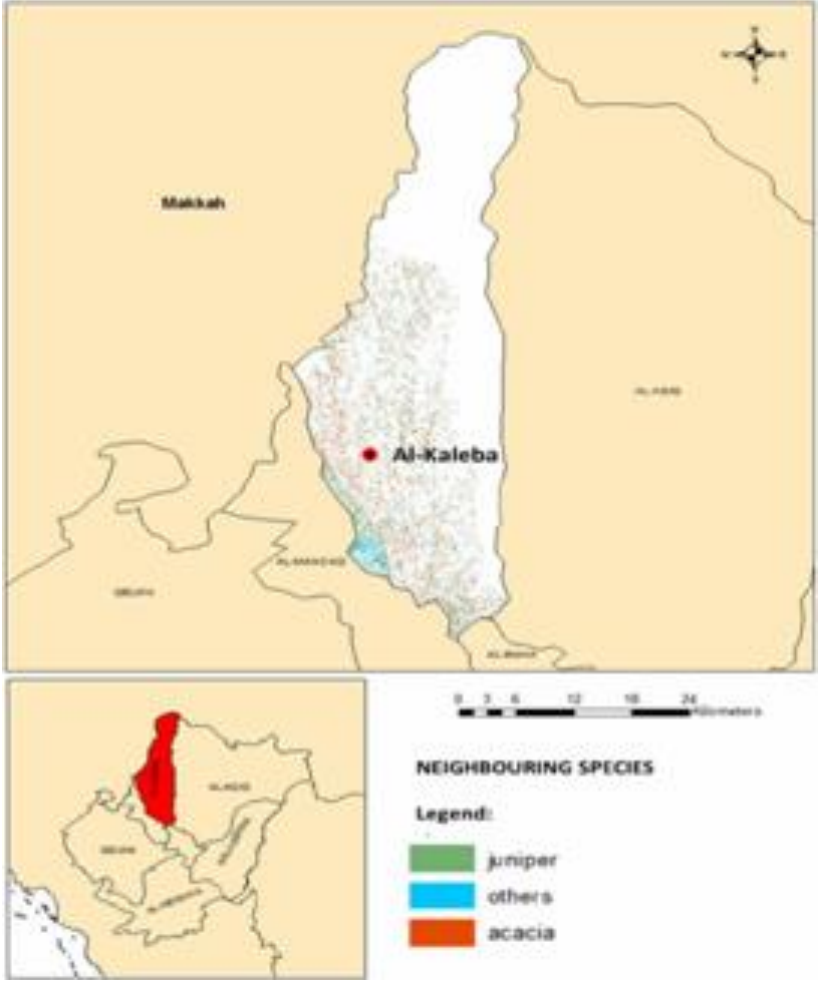

Figure 7: Distribution of neighbouring species in the AlQura district

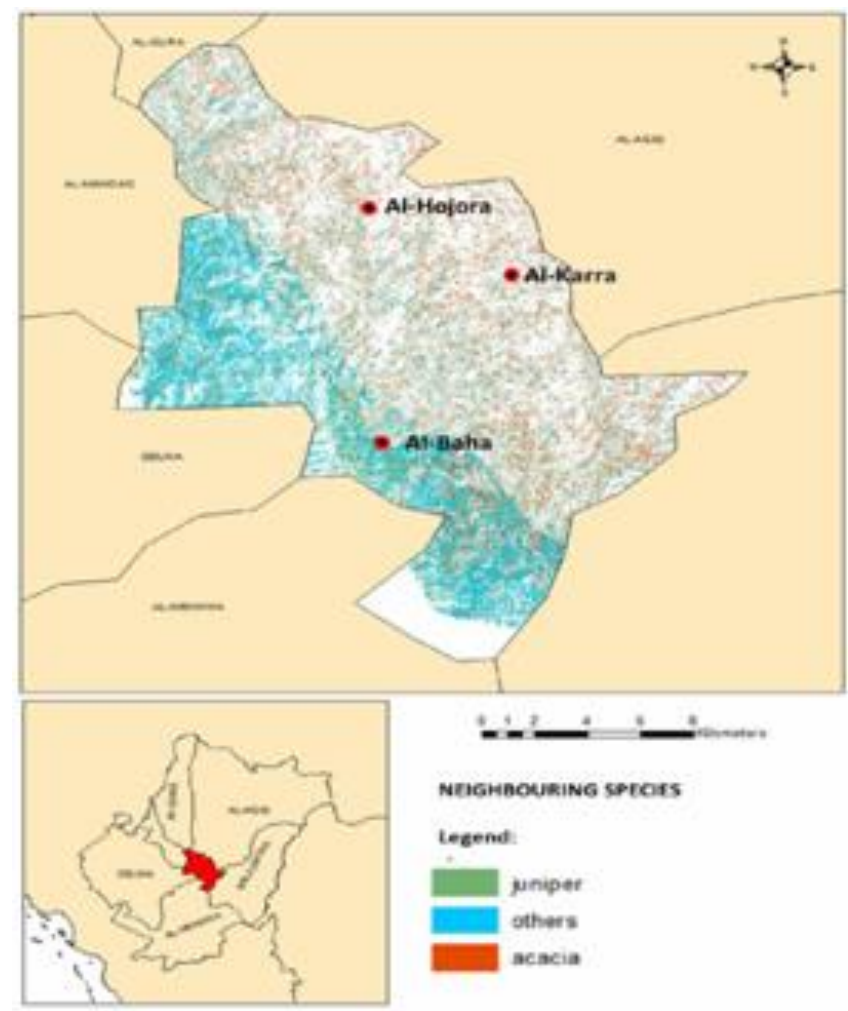

Figure 8: Distribution of neighbouring species in the AlBaha district. 


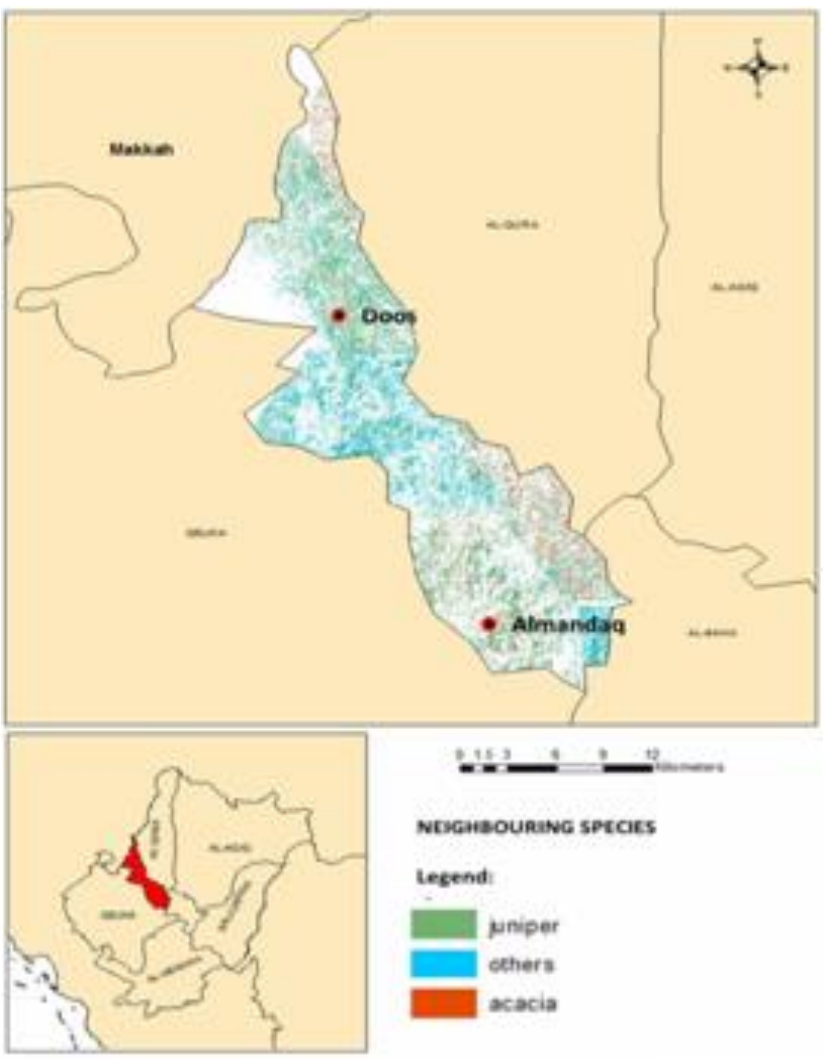

Figure 9: Distribution of neighbouring species in the AlMandaq district

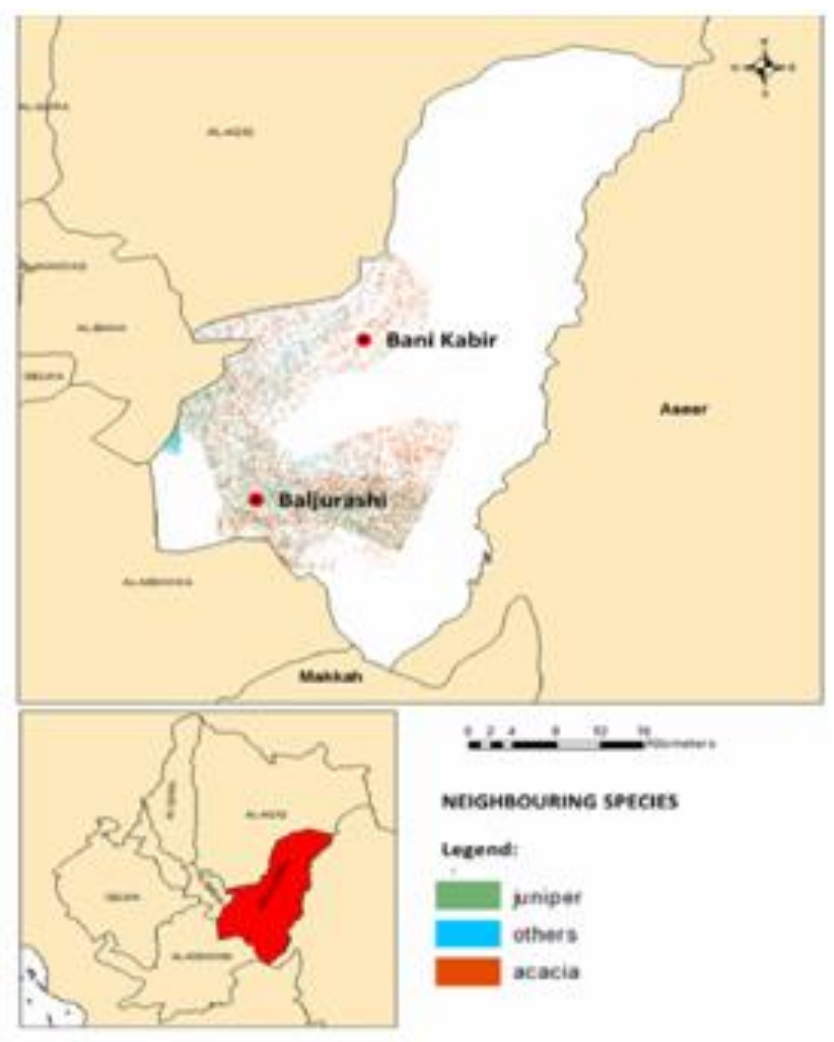

Figure 10: Distribution of neighbouring species in the Baljurashi district

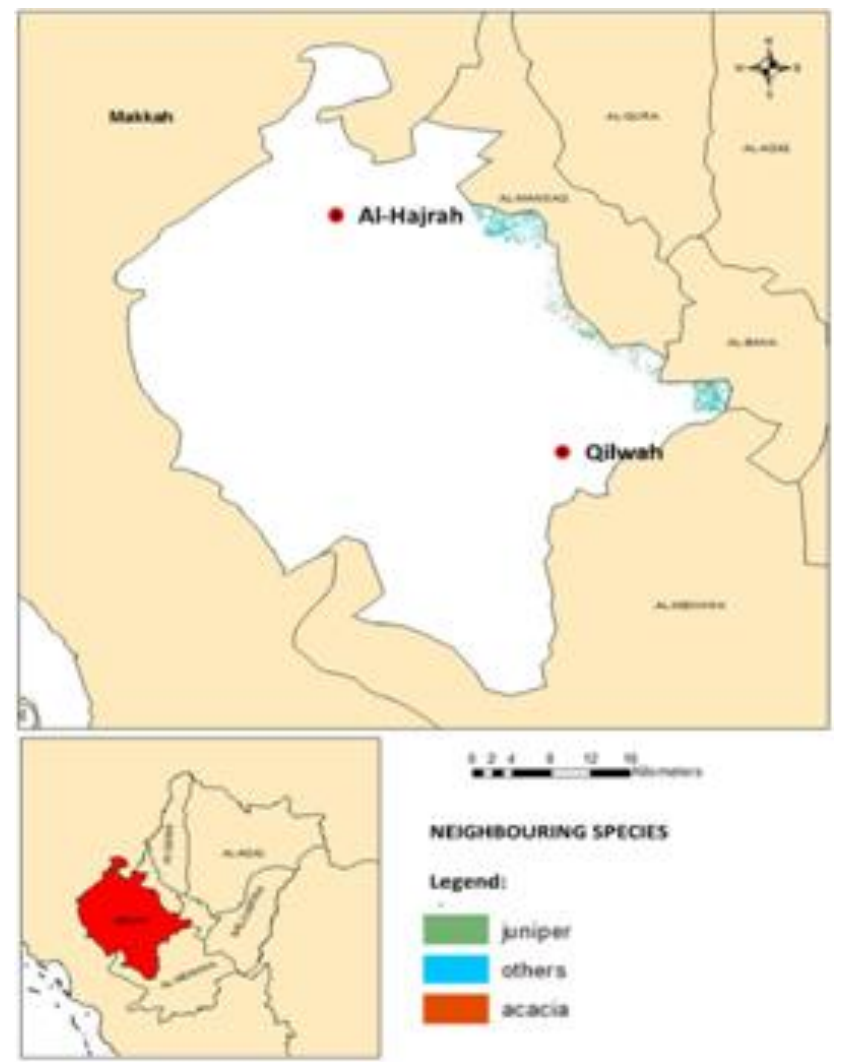

Figure 11: Distribution of neighbouring species in the AlMekhwa district

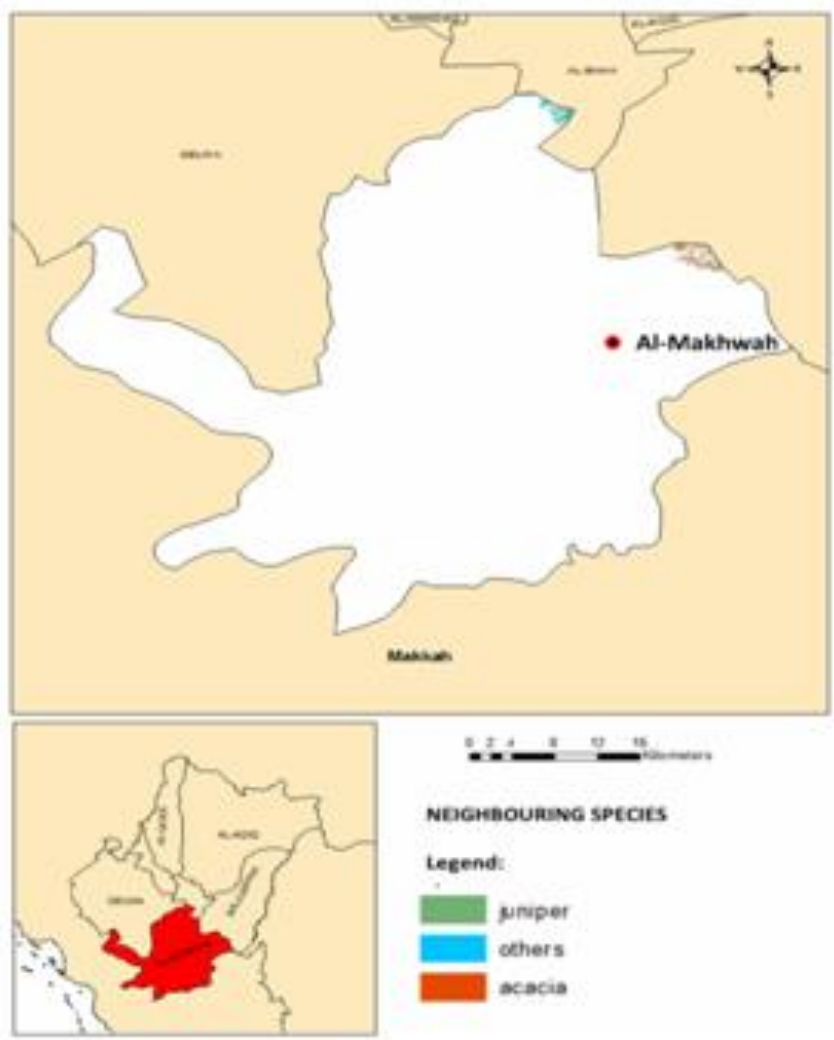

Figure 12: Distribution of neighbouring species in the Qelwa district 


\section{Accuracy Assessment}

The accuracy assessment was conducted according to Congalton (1991).In this study, 73 sampling plots measuring $50 \mathrm{~m} \times 50 \mathrm{~m}$ at the site randomly were stratified based on districts. The results obtained show that out of 469 wild olive trees interpreted on image, 414 trees were found true while 22 acacia and 33 juniper trees were interpreted as wild olive. These figures represent the accuracy of wild olive tree interpretation as $93.7 \%$ for producer accuracy and $88.3 \%$ for user accuracy. The overall accuracy of these interpretation from the PLEIADES image was about $89.2 \%$. Meanwhile, producer and user accuracy for acacia were $87 \%$ and $89.5 \%$, respectively, and $86 \%$ and $90.12 \%$ for juniper, respectively. The overall accuracy of the interpretation of species was $89.2 \%$, with producer and user accuracy for wild olive interpretation being $93.7 \%$ and $88.3 \%$, respectively.

Table 3: Accuracy assessment

\begin{tabular}{|c|c|c|c|c|c|}
\hline \multicolumn{2}{|c|}{} & \multicolumn{4}{|c|}{ Tree numbers at site } \\
\cline { 3 - 6 } \multicolumn{2}{|c|}{$\begin{array}{c}\text { Wild } \\
\text { Olive }\end{array}$} & Acacia & Juniper & Total \\
\hline \multirow{3}{*}{$\begin{array}{c}\text { Tree } \\
\text { numbers } \\
\text { at image }\end{array}$} & $\begin{array}{c}\text { Wild } \\
\text { Olive }\end{array}$ & 414 & 22 & 33 & 469 \\
\cline { 2 - 6 } & Acacia & 12 & 289 & 22 & 323 \\
\cline { 2 - 6 } & Juniper & 16 & 21 & 337 & 374 \\
\cline { 2 - 6 } & Total & 442 & 332 & 392 & 1,166 \\
\hline \multicolumn{6}{|c|}{ Producers Accuracy: $=414 / 442=93.7 \%$} \\
\hline \multicolumn{6}{|c|}{ Users Accuracy: $=414 / 469=88.3 \%$} \\
\hline \multicolumn{6}{|c|}{ Overall Accuracy: $1,040 / 1,166=89.2 \%$} \\
\hline \multicolumn{6}{|c|}{}
\end{tabular}

\section{Discussion}

The information extracted from the high-resolution PLEIADES satellite imagery revealed that there are 717,894 wild olive trees (360 trees per $\left.\mathrm{km}^{2}\right)$ at this study area covering $1,991 \mathrm{~km}^{2}$, with most of them found in mountainous areas in the Al-Mandaq and Al-Baha districts. Al-Khulaidy (2013) referred to this region as the most plantdiverse area in Saudi Arabia. Previously, El-Juhany and Aref (2012), at Al-Mandaq, inventoried all 147-tree species per hectare, whereas this study accounted 613 wild olive trees per $\mathrm{km}^{2}$. This indicates that wild olive is not the main species of vegetation in the Al-Baha region, and many researchers have reported juniper and acacia as the more abundant species.

Earlier, the Al-Baha region was reported as being characterized by highly diverse vegetation particularly in the high mountains, with Juniperus procera woodland and the forests found beside other communities (Al-Aklabi et al., 2016). Hence, this project also aimed to identify whether the wild olive tree associated its occurrence with certain species. In this study, neighbouring species were identified within a five-meter radial distance from wild olives. The result indicates that juniper (40.2\%) and acacia (36.0\%) are the two main species neighbouring wild olives, with acacia found more dominantly in both the districts of Al-Qura and Baljurashi. Distinctly, Qelwa was found to have many others $(42.3 \%)$ as neighbouring species.

The overall accuracy of the interpretation of species was $89.2 \%$, with producer and user accuracy for wild olive interpretation being $93.7 \%$ and $88.3 \%$, respectively.

\section{Conclusion}

This study has provided a detailed overview of the extent and distribution of wild olive trees in the Al-Baha region as well as the species attributes. Results obtained show that there are 717,894 wild olive trees $\left(360\right.$ trees per $\left.\mathrm{km}^{2}\right)$ in the 1,991-ha study area concentrated along the As Sarah mountain that encompasses the districts Al-Qura, AlMandaq, Al-Baha, and the southern part of Baljurashi. This indicates the wild olive trees' preference of highfoggy mountain conditions, which was previously determined, in a first phase project, as a medium-high vegetation density zone.

The occurrence of wild olives can be divided into three zones:

1) Districts of Al-Mandaq and Al-Baha which have higher wild olive density with more juniper neighbouring

2) Districts of Al-Qura and Al-Baljurashi which have lower wild olive density but more acacia neighbouring

3) Districts of Al-Aqiq, Qelwa, and Mekhwa which have the least density of wild olives with more juniper neighbouring except for Qelwa, which has more 'other' species neighbouring

As the life-form distribution of plants growing in arid regions is closely related to its topography and landform (Aldhebiani and Howladar, 2013), this information will be essential to the third phase of the project 'Identifying the Landscape Preference of the Wild Olive in Al-Baha Region'.

\section{Acknowledgements}

This research was funded by the chair of Sheikh Said Ben Ali Alangari for olives research at Albaha University, Albaha, Saudi Arabia. The author also gratefully acknowledges the Deanship of Scientific Research (DSP) at Albaha University for their technical support and extends gratitude to Geoprecision Tech Sdn Bhd (GPT) and Universiti Putra Malaysia (UPM) for their technical help.

\section{References}

[1] Al-Aklabi A., Wali Al-Khulaidi A., Hussain A., and AlSagheer N. (2016) Main vegetation types and plant species diversity along an altitudinal gradient of $\mathrm{Al}$ Baha region, Saudi Arabia, Saudi J Biol Sci., 23(6): 687-697. Published online Mar 2016.

[2] Al-Ghamdi, A. S. (2020a). Classifying and mapping of vegetated area in Al-Bahah region, Saudi Arabia using remote sensing. I. Extent and distribution of ground vegetated cover categories (Under publication).

[3] Al-Ghamdi, A. S. (2020 b). Wild olive tree mapping extent, distribution and basic attributes of wild olive tree at Al-Baha region, Saudi Arabia usingremotesensing technology I. Enumerate, extent, distribution and mapping (Under publication).

[4] Al-Khulaidi A.A. (2013). Flora of Yemen. The Sustainable Natural Resource Management Project (SNRMP II), EPA and UNDP, Republic of Yemen (2013). 
[5] Aldhebiani, A. Y., Howladar S. M. (2013). Floristic diversity and environmental relations in two valleys, south west Saudi Arabia, International Journal of Science and Research (IJSR), 4(2): February 2015, ISSN (Online): 2319-7064.

[6] Apan, A., Young, F. R., Phinn, S., Held, A., and Favier, J. (2004). Mapping olive varieties and within-field spatial variability using high resolution QuickBird imagery. In Proceedings of 12th Australasian Remote Sensing and Photogrammetry Conference, Spatial Science Institute. (12th Australasian Remote Sensing and Photogrammetry Conference, 18-22 October 2004, Fremantle, Australia.)

[7] Besnard, G. B. (2001). Genetic relationships in the olive (Olea europaea L.) reflect multilocal selection of cultivars, Theoretical and Applied Genetics 106(7):1273-82

[8] Besnard, G. and A. Berville (2000). "Multiple origin for Mediterranean olive (Olea europea L. subsp. europea) based upon mitochodrial DNA polymorphisms." Comptes Rendus de l'Academie des Sciences, serie III 323: 173-181.

[9] Breton C, Tersac M, Bervillé A (2006) Genetic diversity and gene flow between the wild olive (oleaster, Olea europaea L.) and the olive: several PlioPleistocene refuge zones in the Mediterranean basin suggested by simple sequence repeats analysis. J Biogeography 33:1916-1928

[10] Congalton R. G. (1991).A review of assessing the accuracy of classifications of remotely sensed data, Remote Sense Environ., 37:35-46.

[11] Congalton, R. G. (1991). Acomparison of sampling schemes used in generating error nmtrices for assessing the accuracy of maps generated from remotely sensed data, Photogramnt. Eng. Remote Sens., 54(5):593-600.

[12] Egbert S.L., Park S., Price K.P., et al. (2002). Using conservation reserve program maps derived from satellite imagery to characterize landscape structure, Comput Electron Agric., 37:141-56.

[13]El-Juhany, L. I. and I. M. Aref (2012). The present status of the natural forests in the southwestern Saudi Arabia 2-Baha forests. World Applied Sciences Journal (ISI Journal), 20(2):271-281. ISSN 1818-4952.

[14] Hamilton, R., Megown, K., Lachowski, H., Campbell, R. (2006). Mapping Russian olive: Using remote sensing to map an invasive tree. RSAC-0087-RPT1. Salt Lake City, UT: U.S. Department of Agriculture Forest Service, Remote Sensing Application Center. 7.

[15] Hexagonspatial (2016), Erdas Imagine, Website: https://www.hexagongeospatial.com/products/produce rsuite/erdas-imagine.

[16] Jensen, J.R. (2005)," Introductory Digital Image Processing ( $3^{\text {rd }}$ Edition)" Prentice Hall.

[17] Katz, G.L., Shafroth, P.B. (2003). Biology, ecology and management of Elaeagnus angustifolia L. (Russian olive) in western North America, Wetlands, 23:763777.

[18] Krejcie, R. V., and Morgan, D. W. (1970). Determining sample size for research activities, Educational and Psychological Measurement, 30: 607-610.

[19] Langley S.K., Cheshire H.M., Humes K.S. (2001). A comparison of single date and multitemporal satellite image classifications in a semi-arid grassland, $J$ Arid
Environ, 49:401-11.

[20] Lumaret R, Ouazzani N, Michaud H, Vivier G, Deguilloux M-F, Di Giusto F (2004) Allozyme variation of oleaster populations (wild olive tree) (Olea europaea L.) in the Mediterranean Basin. Heredity 92:343-352.

[21] Nordberg M.L., and Evertson J. (2003). Vegetation index differencing and linear regression for change detection in a Swedish mountain range using Landsat TM and ETM+ imagery. Land Degradation \& Development, 16:139-149.

[22] Peña-Barragán, J.M., Jurado-Expósito, M., LópezGranados, F., Atenciano, S., Sánchez-de la Orden, M., García-Ferrer, A. and García-Torres, L. (2004). Assessing land-use in olive groves from aerial photographs, Agriculture, Ecosystems \& Environment, 103(1): 117-122.

[23] Price, J.P. (2004). Floristic biogeography of the Hawaiian Islands-Influences of area, environment and paleogeography, Journal of Biogeography,31: 487500.

[24]Rapp C. S. (1996). Image processing and image enhancement, Texas.

[25] Salant, P., and Dillman, D.A. (1994). How to conduct your own survey. New York: John Wiley \& Sons, Inc.

[26] Stannard, M., Ogle, D., Holzworth, L., Scianna J., Sunleaf, E. (2002). History, biology, ecology, suppression and revegetation of Russian-olive sites (Elaeagnus angustifolia L.). Plant Materials Technical Note No. 47. Boise, ID. U.S. Department of Agriculture, Natural Resources Conservation Service, 14.

[27] Xiao, X.M., Zhang, Q., Braswell, B., et al. (2004). Modeling gross primary production of temperate deciduous broadleaf forest using satellite images and climate data. Remote Sens Environ, 1:256-70. 